\title{
Chronic Exposure to Particulate Nickel Induces Neoplastic Transformation in Human Lung Epithelial Cells
}

\author{
Amie L. Holmes ${ }^{1,2,3}$, Therry The ${ }^{1,2}$, Kelsey Thompson ${ }^{1,2}$, Michael Mason ${ }^{4}$, Sanjeev Kandpal ${ }^{4}$, \\ Tongzhang Zheng ${ }^{5}$ and John Pierce Wise, Sr. ${ }^{1,2,3, *}$
}

1 Wise Laboratory of Environmental and Genetic Toxicology, University of Southern Maine, Portland, ME 04104, USA; E-Mails: amie.holmes@maine.edu (A.L.H.); therry.the@maine.edu (T.T.); kelsey.thompson@maine.edu (K.T.)

2 Maine Center for Toxicology and Environmental Health, University of Southern Maine, Portland, ME 04104, USA

3 Department of Applied Medical Science, 96 Falmouth St., University of Southern Maine, Portland, ME 04104, USA

4 Department of Chemical and Biological Engineering, University of Maine, Orono, ME 04469, USA; E-Mails: mmason@umche.maine.edu (M.M.); skandpal@umche.maine.edu (S.K.)

5 Department of Environmental Health Sciences, Yale School of Public Health, New Haven, CT 06520, USA; E-Mail: tongzhang.zheng@yale.edu

* Author to whom correspondence should be addressed; E-Mail: john.wise@maine.edu; Tel.: +1-207-228-8050; Fax: +1-207-228-8089.

Received: 16 October 2013; in revised form: 6 November 2013 / Accepted: 14 November 2013 / Published: 25 November 2013

\begin{abstract}
Nickel is a well-known human lung carcinogen with the particulate form being the most potent; however, the carcinogenic mechanism remains largely unknown. Few studies have investigated the genotoxicity and carcinogenicity of nickel in its target cell, human bronchial epithelial cells. Thus, the goal of this study was to investigate the effects of particulate nickel in human lung epithelial cells. We found that nickel subsulfide induced concentration- and time-dependent increases in both cytotoxicity and genotoxicity in human lung epithelial cells (BEP2D). Chronic exposure to nickel subsulfide readily induced cellular transformation, inducing 2.55, 2.9 and 2.35 foci per dish after exposure to $1,2.5$ and $5 \mu \mathrm{g} / \mathrm{cm}^{2}$ nickel subsulfide, respectively. Sixty-one, 100 and 70 percent of the foci isolated from $1,2.5$, and $5 \mu \mathrm{g} / \mathrm{cm}^{2}$ nickel subsulfide treatments formed colonies in soft agar and the degree of soft agar colony growth increased in a concentration-dependent
\end{abstract}


manner. Thus, chronic exposure to particulate nickel induces genotoxicity and cellular transformation in human lung epithelial cells.

Keywords: particulate nickel; nickel subsulfide; chromosome damage; transformation

\section{Introduction}

Exposure to nickel is widespread in industrial and environmental settings. Due to its color and anti-corrosive properties, nickel is used heavily in metal alloys for making coins, jewelry, stainless steel, and electroplating [1]. Additionally, nickel is released into the atmosphere as a result of fossil fuel combustion [1]. Nickel is present in over half of the hazardous waste sites listed on the Environmental Protection Agency's (EPA) National Priorities List. The prevalence of nickel in the environment along with its carcinogenic potential makes it a significant public health concern.

Epidemiologic, whole animal and cell culture studies indicate that nickel is a human lung carcinogen [1-3]. Numerous epidemiology studies on nickel workers show that inhalation exposure to nickel, particularly insoluble nickel compounds, induce upper and lower respiratory tract cancers [1-3]. Animal studies support the epidemiological findings and show that chronic exposure to particulate nickel compounds readily induced alveolar/bronchiolar adenomas and carcinomas in rats, while exposure to soluble nickel sulfate did not increase tumor incidence [4,5].

Studies indicate that the particulate form of nickel is more carcinogenic than soluble nickel compounds. This difference appears to be due to differences in nickel uptake. Soluble nickel ions are poorly absorbed across the cell membrane while crystalline particulate nickel compounds are readily phagocytized into the cells releasing nickel ions in close proximity to the nucleus [6,7].

The major target organ for particulate nickel-induced carcinogenesis is the respiratory tract inducing primarily squamous cell carcinomas after inhalation exposure [8]. Particulate nickel impacts and persists in the lungs while the soluble nickel compounds are more readily cleared from the lungs [9]. However, despite the fact that the lung is the major target organ, little is known about the carcinogenic and genotoxic impact of particulate nickel on human lung epithelial cells. No studies have investigated the ability of particulate nickel to damage DNA in human lung epithelial cells and only one other study has investigated the transforming effects of particulate nickel on human lung epithelial cells. That one study [10], showed that nickel can transform SV40-immortalized human lung cells and noted loss of contacted-inhibited growth, but did not quantify the amount of foci formation so the potency of nickel was uncertain. Accordingly, this study investigated the ability of particulate nickel to induce genotoxic damage and morphological transformation in human lung epithelial cells.

\section{Experimental Section}

\subsection{Chemicals and Reagents}

Crystalline nickel subsulfide was purchased from Santa Cruz (Dallas, TX, USA). LHC8 and Gurr's buffer tablets were purchased from Life Technologies Corp (Carlsbad, CA, USA). Ultra saline A, trypsin-EDTA and trypsin neutralizing solution were purchased from Lonza (Walkersville, MD, USA). 
Colcemid and potassium chloride were purchased from Sigma (St. Louis, MO, USA). Crystal violet, acetic acid and methanol were purchased from J.T. Baker (Phillipsburg, NJ, USA). 4-Nitro-blue tetrazolium chloride was purchased from Roche (Indianapolis, IN, USA). Agarose, tissue culture flasks, dishes and all plastic ware were purchased from Becton, Dickinson and Company (Franklin Lakes, NJ, USA).

\subsection{Cells and Cell Culture}

BEP2D cells were used in all experiments as a model bronchial epithelial cell line. These cells were immortalized using the human papillomavirus 18 [11] and exhibit a near diploid stable karyotype and are nontumorigenic. BEP2D cells were maintained in serum-free LHC8 media and subcultured at least once a week using trypsin-EDTA and trypsin neutralizing solution. All experiments were performed on logarithmically growing cells. Mycoplasma testing was performed once a month.

\subsection{Nickel Subsulfide Preparation}

Nickel subsulfide, $\mathrm{Ni}_{3} \mathrm{~S}_{2}$, (CAS\# 12035-72-2, reagent purity 99.7\%) was used as a model particulate nickel compound. Particle size was determined using a Malvern-Morphologi dry particle sizer and the diameter ranged from 0.22 to $75 \mu \mathrm{m}$ with a mean of $2 \mu \mathrm{m}$. This particle size is consistent with previous studies that indicate that particles with a diameter of $2-4 \mu \mathrm{m}$ are more readily phagocytized into the cell than larger particles with a diameter of 5-6 $\mu \mathrm{m}$ [12].

Nickel subsulfide particles were suspended in cold sterile-filtered water and spun overnight with a magnetic stir bar. Dilutions were made from the stock using a vortex mixer and appropriate volumes were dispensed into cell cultures. Nickel subsulfide concentrations ranged from 1 to $10 \mu \mathrm{g} / \mathrm{cm}^{2}$.

\subsection{Cytotoxicity Assay}

Cytotoxicity of nickel subsulfide was determined using the clonogenic survival assay as previously described [13]. Clonogenic survival assay measures the reduction in plating efficiency in treated cells compared to control cells. Four dishes were reseeded per concentration and each experiment was performed at least three times.

\subsection{Clastogenicity Assay}

Chromosome damage was assessed as a measure of chromosomal aberrations in control and treated cells as previously described [13]. Cells were analyzed for chromatid breaks, isochromatid breaks, chromatid exchanges, dicentrics, double minutes, acentric fragments, fragmented chromosomes and centromere spreading. One hundred metaphases were analyzed per concentration and each experiment was performed at least three times.

\subsection{Transformation Assay}

Loss of contact inhibition and anchorage-independent growth are two hallmarks of cellular transformation in vitro. Subsequently, assays for foci formation and soft agar growth were used to assess nickel subsulfide-induced transformation in human lung epithelial cells using published 
methods [14]. Five $100 \mathrm{~mm}$ dishes were seeded with 50,000-100,000 cells for each concentration and treated with $0,1,2.5$ or $5 \mu \mathrm{g} / \mathrm{cm}^{2}$ nickel subsulfide for $120 \mathrm{~h}$. At the end of treatment, cells were washed three times with ultra saline A to remove any undissolved particles, trypsinized and reseeded into ten $60 \mathrm{~mm}$ dishes per concentration at a density of 50,000 cells. Dishes were monitored for foci formation and cultured for a maximum of 10 passages. Once foci formation was detected, foci were cloned. A sterile cloning cylinder with one edge coated with silicone grease was placed around the selected focus and $40 \mu \mathrm{L}$ of trypsin was added to the cloning cylinder well. The focus cells were transferred into a 24 well plate and further expanded into a cell line.

To determine anchorage-independent growth, 50,000 control or foci cells were suspended in $0.35 \%$ agar and plated onto a $0.6 \%$ agar base layer. After seeding, dishes were checked under the microscope to confirm that no large cell clumps were present that could be mistaken as a colony. Cells were fed once a week for six weeks and monitored for colony formation. At the end of six weeks, dishes were stained with 5\% 4-nitro-blue tetrazolium chloride to visualize and count the colonies in each dish.

\subsection{Statistical Analysis}

The Student's $t$ test was used to calculate $p$ values to determine statistical differences between control and treated cells and between time points. $p$ value less than 0.05 was the criterion for statistical significance. Since all comparisons among means were considered to be of substantive interest a priori, no adjustment for multiple comparisons was incorporated into the analysis [15].

\section{Results and Discussion}

\subsection{Nickel Subsulfide Is Cytotoxic to Human Lung Epithelial Cells}

To first evaluate the cytotoxic effects of particulate nickel on human lung epithelial cells, we treated BEP2D cells with nickel subsulfide for 24 or $120 \mathrm{~h}$. We found nickel subsulfide induced a concentration-dependent decrease in cell survival in human lung epithelial cells with chronic exposures inducing more toxicity only after exposures to higher concentrations of nickel subsulfide (Figure 1). For example, exposure to $1 \mu \mathrm{g} / \mathrm{cm}^{2}$ nickel subsulfide for 24 or $120 \mathrm{~h}$ induced 67 and 71 percent relative survival, respectively, while exposure to $10 \mu \mathrm{g} / \mathrm{cm}^{2}$ induced 15 and 2 percent relative survival, respectively. These data are consistent with previous studies indicating nickel subsulfide is cytotoxic to mammalian cells $[12,16]$. From the cytotoxicity curve, we chose to focus on $1,2.5$ and $5 \mu \mathrm{g} / \mathrm{cm}^{2}$ nickel subsulfide in subsequent experiments as these concentrations produced low to medium levels of toxicity.

\subsection{Nickel Subsulfide Is Clastogenic to Human Lung Epithelial Cells}

Our next step was to determine the clastogenicity of nickel subsulfide in human lung epithelial cells. We found that nickel subsulfide induced both a concentration- and time-dependent increase in chromosome damage in BEP2D cells (Figure 2). Exposure to 1, 2.5 or $5 \mu \mathrm{g} / \mathrm{cm}^{2}$ nickel subsulfide for $24 \mathrm{~h}$ induced 6, 11 and 17 percent of metaphases with damage and 7, 12 and 21 total aberrations in 100 metaphases, respectively (Figure 2a), while chronic exposure induced 11, 17 and 26 percent of metaphases with damage and 13, 19 and 30 total aberrations, respectively (Figure 2b). In order to 
determine the spectrum of damage, metaphase chromosomes were analyzed for chromatid and isochromatid lesions, acentric fragments, chromatid exchanges, dicentrics, double minutes, centromere spreading and chromosome fragmentation. We found that chromatid lesions were the most prevalent form of damage while all other forms of damage were rarely observed. No chromatid exchanges, acentric fragments or chromosome fragmentation were observed after nickel subsulfide exposure.

Figure 1. Cytotoxicity of crystalline nickel subsulfide in human lung epithelial cells. This figure shows that crystalline nickel subsulfide induced a concentration-dependent increase in cytotoxicity in human lung epithelial cells after a 24 or $120 \mathrm{~h}$ exposure. Data represent an average of 3-5 experiments $+/-$ the standard error of the mean. All data points are statistically different from control $(p<0.05)$. * Statistically different from 120 h exposure $(p<0.05)$.



Figure 2. Clastogenicity of nickel subsulfide in human lung epithelial cells. This figure shows that acute and chronic exposure to crystalline nickel subsulfide induced a concentration-dependent increase in chromosome damage in human lung epithelial cells. (a) $24 \mathrm{~h}$. (b) $120 \mathrm{~h}$. Data represent an average of three independent experiments $+/-$ the standard error of the mean. All data points are statistically different from control $(p<0.05)$. Percent of metaphases with damage and total aberrations in 100 metaphases for 2.5 and $5 \mu \mathrm{g} / \mathrm{cm}^{2}$ nickel subsulfide for $24 \mathrm{~h}$ are statistically different from $120 \mathrm{~h}(p<0.05)$.

To our knowledge, this is the first study to investigate the clastogenicity of nickel subsulfide in general and more specifically in human lung epithelial cells, the target cell of particulate nickel. Our data are consistent with previous mammalian cell culture studies showing that nickel sulfide, a similar particulate nickel compound, induces a concentration- and time-dependent increase in chromosome damage in rodent cells, but the spectrum of damage differs between rodent and human cells [17-20]. Similar to human cells, particulate nickel induced chromosome breaks in rodent cells, but there was also an induction of chromatid exchanges and chromosome fragmentation that was not observed in the human lung epithelial cells after particulate nickel exposure (Table 1) [17-19].

One possible explanation for the differences in chromatid exchange and fragmentation induction may be due to the different particulate nickel compounds used. We used nickel subsulfide $\left(\mathrm{Ni}_{2} \mathrm{~S}_{3}\right)$ in our study while the rodent cell studies used nickel sulfide (NiS) [17-20]. However, this explanation seems unlikely since both crystalline nickel subsulfide and nickel sulfide are potent human lung carcinogens and appear to exhibit a similar mode of action. Studies indicate that both compounds exhibit similar levels of cytotoxicity, particle uptake, reactive oxygen species (ROS) generation and cell transforming ability in rodent cells [12,21,22].

Another possible explanation is differences in cell types. Chromatid exchanges are a more complex form of damage requiring the formation and misrepair of DNA double strand breaks. Studies indicate that humans have more efficient repair mechanisms compared to shorter-lived species, such as rodents [23]. Thus, it is possible that human lung epithelial cells are capable of more efficiently and correctly repairing particulate nickel-induced DNA double strand breaks compared to rodent cells. In addition, the $\mathrm{CHO}$ cells used in these previous studies exhibited a remarkably high background chromosome damage level of 17 percent, indicating they are more unstable than human cells (Table 1) $[17,18]$ which could also explain why they have more exchanges.

It is also interesting to note that we did not see any chromosome fragmentation after nickel subsulfide exposure. The previous studies in $\mathrm{CHO}$ cells reported nickel sulfide induced fragmentation in the heterochromatic long arm of the $\mathrm{X}$ chromosome $[17,18]$. The reasons for the differences in chromosome fragmentation are uncertain. In the $\mathrm{CHO}$ cells, chromosome fragmentation was specific to the X chromosome, which is primarily heterochromatic. Fragmentation was not observed in any of the other chromosomes that exhibit smaller regions of heterochromatic DNA. In humans, the centromeric and telomeric regions of all chromosomes along with larger portions of the 1, 9, 16, Y and second $\mathrm{X}$ chromosomes are heterochromatic [24]. Besides the second $\mathrm{X}$ chromosome, no other chromosomes are primarily heterochromatin. BEP2D cells were derived from a male donor and therefore, do not contain a second heterochromatic copy of the X chromosome [11]. Thus, the lack of fragmentation in the human cells may be due to differences in the extent of heterochromatic DNA in human chromosomes compared to the $\mathrm{CHO}$ chromosomes.

In our study, chronic exposure to nickel subsulfide induced a small but statistically significant increase in dicentrics (Table 1). This is consistent with previous studies in CHO cells showing longer exposures to particulate nickel induce dicentric chromosomes [17,18]. Dicentric chromosomes form when the ends of two chromosomes fuse together and are a more complex and deleterious lesion. The presence of dicentric chromosomes in mitosis can form bridges that subsequently break as the cell divides into two daughter cells and contribute to chromosome instability [25]. Thus, breakage-fusion-bridge cycles may play a role in particulate nickel-induced chromosome instability. 
Table 1. Spectrum of chromosome aberrations induced by nickel subsulfide after 24 or $120 \mathrm{~h}$ exposure.

\begin{tabular}{|c|c|c|c|c|c|c|c|}
\hline $\begin{array}{c}\mathrm{Ni}_{3} \mathrm{~S}_{2} \text { concentration } \\
\left(\mu \mathrm{g} / \mathrm{cm}^{2}\right)\end{array}$ & $\begin{array}{c}\text { Chromatid } \\
\text { lesion }\end{array}$ & $\begin{array}{c}\text { Isochromatid } \\
\text { lesion }\end{array}$ & $\begin{array}{c}\text { Chromatid } \\
\text { exchange }\end{array}$ & Dicentric & $\begin{array}{l}\text { Double } \\
\text { minute }\end{array}$ & $\begin{array}{c}\text { Centromere } \\
\text { spreading }\end{array}$ & Total damage \\
\hline \multicolumn{8}{|l|}{24 h Exposure } \\
\hline 0 & $1.7 \pm 0.3$ & $0 \pm 0$ & $0 \pm 0$ & $0 \pm 0$ & $0 \pm 0$ & $0 \pm 0$ & $1.7 \pm 0.3$ \\
\hline 1 & $5.3 \pm 0.9 *$ & $0.3 \pm 0.3$ & $0 \pm 0$ & $0.7 \pm 0.3$ & $0.3 \pm 0.3$ & $0 \pm 0$ & $6.7 \pm 0.9 *$ \\
\hline 2.5 & $11.3 \pm 1.3 *$ & $0.7 \pm 0.7$ & $0 \pm 0$ & $0 \pm 0$ & $0.3 \pm 0.3$ & $0 \pm 0$ & $12.3 \pm 0.9 *$ \\
\hline 5 & $18.7 \pm 0.3 *$ & $1.3 \pm 0.3 *$ & $0 \pm 0$ & $0 \pm 0$ & $0 \pm 0.3$ & $0.3 \pm 0.3$ & $21.7 \pm 0.3 *$ \\
\hline \multicolumn{8}{|l|}{120 h Exposure } \\
\hline 0 & $2.3 \pm 0.5$ & $0 \pm 0$ & $0 \pm 0$ & $0 \pm 0$ & $0 \pm 0$ & $0 \pm 0$ & $2.8 \pm 0.5$ \\
\hline 1 & $10.7 \pm 3.7 *$ & $0.3 \pm 0.3$ & $0 \pm 0$ & $0.7 \pm 0.3$ & $1.7 \pm 0.7 *, \dagger$ & $0 \pm 0$ & $13.3 \pm 3.3 *$ \\
\hline 2.5 & $15.7 \pm 4.1 *$ & $1.0 \pm 0.5$ & $0 \pm 0$ & $1.3 \pm 0.3 * \dagger$ & $1.3 \pm 0.7$ & $0 \pm 0$ & $19.0 \pm 1.5^{*, \dagger}$ \\
\hline 5 & $26.3 \pm 1.5 * \dagger$ & $0.3 \pm 0.3$ & $0 \pm 0$ & $1.3 \pm 1.3$ & $1.0 \pm 0 *$ & $1 \pm 0.6$ & $30.3 \pm 1.8^{*, \dagger}$ \\
\hline
\end{tabular}

* Statistically different from control $(p<0.05) ;{ }^{\dagger}$ statistically different from $24 \mathrm{~h}(p<0.05)$. 
The mechanism of particulate nickel-induced chromosome damage remains unknown. Nickel only weakly binds to DNA and is not considered mutagenic [26,27]. Thus, direct binding of Ni ions to the DNA is likely not responsible for the induction of DNA double strand breaks and subsequent chromosome aberrations observed in metaphase cells. Nickel sulfide and nickel subsulfide induce ROS suggesting that ROS generation may play a role in particulate nickel-induced chromosome aberrations [22,28]. Antioxidant studies with nickel sulfide show that vitamin E reduces nickel sulfide-induced chromosome damage but does not eliminate it, indicating that only a portion of particulate nickel-induced chromosome damage is due to ROS generation [20]. Another mechanism of chromosome induction may be from nickel's interaction with histone proteins in the heterochromatin [19,29].

\subsection{Nickel Subsulfide Induces Transformation in Human Lung Epithelial Cells}

Foci formation in adherent cultured cells is indicative of loss of contact inhibition and morphological transformation [30]. BEP2D cells grow as an adherent monolayer and exhibit contact inhibited growth when the cells reach confluence. When cells lose contact inhibition, they continue to grow and pile up on top of one another forming a focus of growth. For transformation, we focused on chronic exposure because of the increased chromosome damage observed after $120 \mathrm{~h}$ and more chronic exposures better mimic human exposures. We found that exposure to nickel subsulfide for $120 \mathrm{~h}$ induced foci formation in BEP2D cells (Figure 3 and Table 2). For example, exposure to 1, 2.5 or $5 \mu \mathrm{g} / \mathrm{cm}^{2}$ nickel subsulfide for $120 \mathrm{~h}$ induced 2.5, 2.9 and $2.3 \mathrm{foci} /$ dish (Table 2), while no foci were observed in the control dishes. Foci formation did not increase in a completely concentration-dependent manner, but this has been observed with other metals where the highest concentration yields fewer foci [31,32]. This outcome is most likely due to the higher degree of cytotoxicity at the highest dose.

Figure 3. Representative pictures of nickel subsulfide-induced foci formation. This figure show representative pictures of control and nickel subsulfide-induced foci. (a) Control cells. (b) Focus produced after exposure to $1 \mu \mathrm{g} / \mathrm{cm}^{2}$ nickel subsulfide. (c) Focus produced after exposure to $2.5 \mu \mathrm{g} / \mathrm{cm}^{2}$ nickel subsulfide.

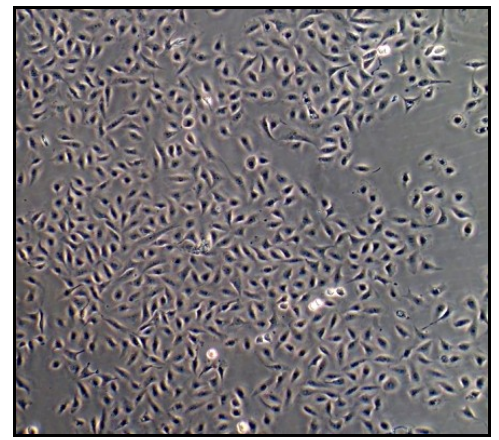

(a)



(b)

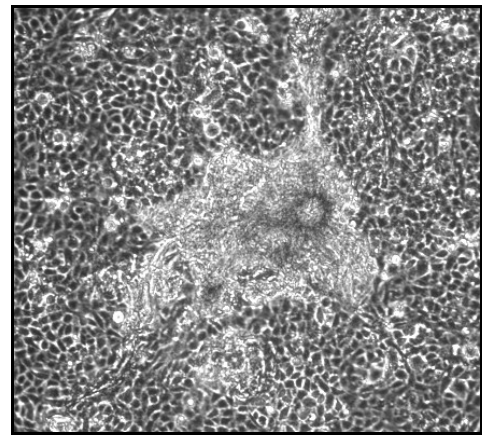

(c) 
Table 2. Transformation of human lung epithelial cells by nickel subsulfide.

\begin{tabular}{ccccc}
\hline $\begin{array}{c}\text { Nickel subsulfide } \\
\text { concentration }\left(\boldsymbol{\mu g} / \mathbf{c m}^{2}\right)\end{array}$ & $\begin{array}{c}\text { Exposure } \\
\text { time }\end{array}$ & $\begin{array}{c}\text { Foci frequency } \\
\text { foci/dish }\end{array}$ & $\begin{array}{c}\text { Number of foci } \\
\text { isolated }\end{array}$ & $\begin{array}{c}\text { Percentage of foci with } \\
\text { growth in soft agar }\end{array}$ \\
\hline 0 & $120 \mathrm{~h}$ & $0(0 / 20)$ & $27 / 27^{\dagger}$ & $0 \%$ \\
1 & $120 \mathrm{~h}$ & $2.55(51 / 20) *$ & $51 / 51$ & $61 \%(26 / 43)$ \\
2.5 & $120 \mathrm{~h}$ & $2.9(29 / 10) *$ & $27 / 29$ & $100 \%(27 / 27)$ \\
5 & $120 \mathrm{~h}$ & $2.35(47 / 20) *$ & $44 / 47$ & $70 \%(31 / 44)$ \\
\hline
\end{tabular}

* Statistically different from control $(p<0.05) ;{ }^{\dagger}$ randomly cloned area.

Twenty-seven areas in the control dishes and 43, 29 and 44 foci were isolated from 1, 2.5 and $5 \mu \mathrm{g} / \mathrm{cm}^{2}$ nickel subsulfide dishes for further testing. As depicted in Figure 3, untreated control cells grew in a flat monolayer (Figure 3a) while cells exposed to nickel subsulfide formed foci in as little as one week after treatment and all treated dishes exhibited foci within three weeks after treatment (Figure 3b,c). Foci exhibited a distinct morphology compared to surrounding cells with cells piling up to form a massive opaque multi-layered focus of growth. Unlike previous studies that categorized foci produced in $\mathrm{C} 3 \mathrm{H} 10 \mathrm{~T} 1 / 2$ mouse embryonic fibroblast cells after nickel subsulfide treatment into type I, II or III [21,26,27], nickel subsulfide-induced foci in human lung epithelial cells did not resemble these morphological classifications, and thus, could not be classified in this manner.

Another hallmark of cellular transformation is the acquisition of anchorage-independent growth. Normal BEP2D cells require a surface on which to attach, flatten out and divide while transformed cells can grow suspended in soft agar and do not need a surface to attach to. Anchorage-independent growth in lung carcinomas correlates well with both tumorigenicity and invasiveness [33]. We tested the control cells and isolated nickel subsulfide-induced foci for growth in soft agar and found that between $61 \%$ and $100 \%$ of the nickel-induced foci exhibited anchorage-independent growth while none of the control cells acquired the ability to grow in soft agar (Table 2, Figure 4). As with foci formation, the percentage of foci with growth in soft agar did not exhibit a concentration-dependent increase but when we investigated the degree of soft agar growth, we found a concentration-dependent increase (Table 3). For example, foci derived from $1 \mu \mathrm{g} / \mathrm{cm}^{2}$ nickel subsulfide exhibited less than 20 soft agar colonies per dish, while foci derived from $5 \mu \mathrm{g} / \mathrm{cm}^{2}$ nickel subsulfide primarily exhibited greater than 20 colonies per dish (Table 3). Thus, despite the lack of a dose response in regards to foci formation and percentage of foci with growth in soft agar, increasing nickel subsulfide concentrations induced a more robust anchorage-independent phenotype which correlates to tumorigenicity [33].

This is the first study to report loss of contact inhibition in a human lung epithelial cell line after particulate nickel exposure and the first to report anchorage-independent growth after nickel subsulfide exposure in its target cell, human lung epithelial cells. This outcome with nickel subsulfide is consistent with the one previous study which investigated nickel sulfide-induced transformation [10]. However, we found continuous exposure to nickel subsulfide for five days induced foci formation in human lung epithelial cells between passages 1 and 3 , but that study did not observe foci until the $35^{\text {th }}$ passage and did not quantify or isolate the foci. One possible explanation for the difference in foci formation time may be differences in exposure regimen or particulate nickel compound. We continuously exposed cells to nickel subsulfide for five days, while they exposed cells to six rounds of a $48 \mathrm{~h}$ nickel sulfide treatment followed by a recovery period spanning over 20 days. It may be that 
continuous nickel exposure is more potent than a repeated exposure, or nickel subsulfide is more potent than nickel sulfide, or a combination of the two.

Figure 4. Representative pictures of anchorage-independent cell growth in nickel subsulfide-induced foci cells. This figure shows representative pictures of 4-nitro-blue tetrazolium chloride-stained colonies in soft agar dishes. (a) Control. (b) Foci cells isolated from $1 \mu \mathrm{g} / \mathrm{cm}^{2}$ nickel subsulfide. (c) Foci cells isolated from $2.5 \mu \mathrm{g} / \mathrm{cm}^{2}$ nickel subsulfide. (d) Foci cells isolated from $5 \mu \mathrm{g} / \mathrm{cm}^{2}$ nickel subsulfide. (e,f) Soft agar colonies at $100 \times$ magnification.

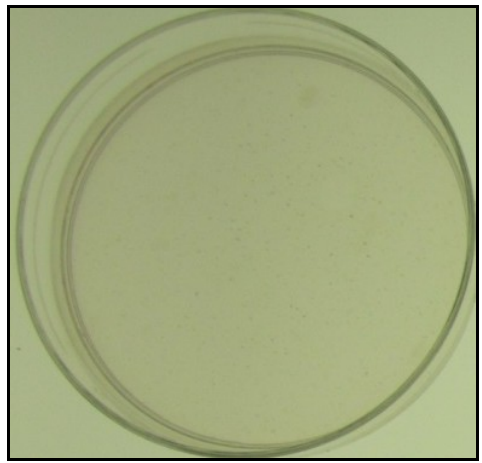

(a)

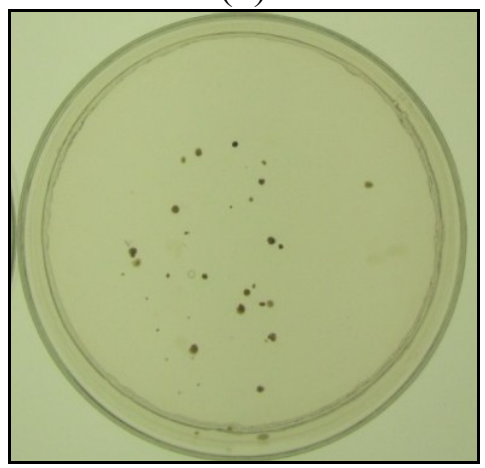

(d)

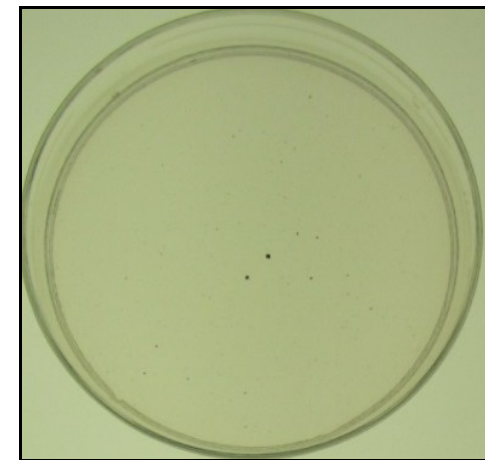

(b)

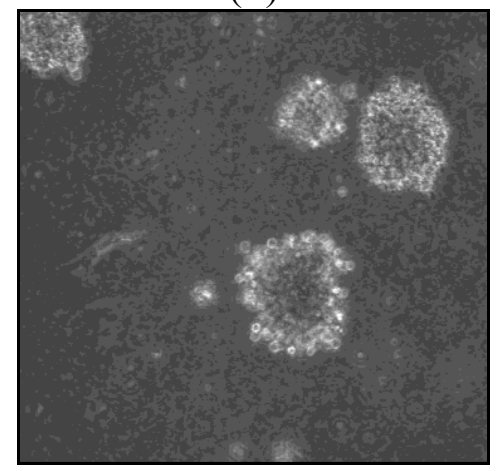

(e)

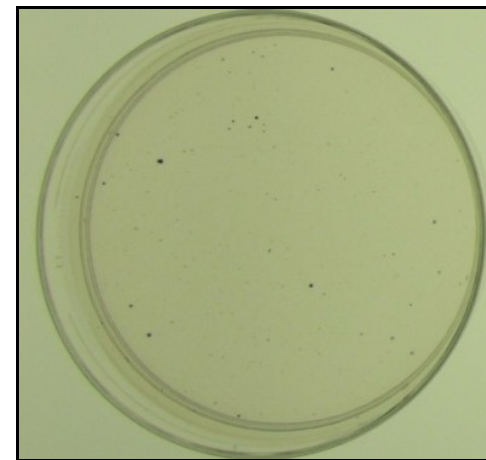

(c)



(f)

Table 3. Anchorage-independent growth of nickel subsulfide-induced foci.

\begin{tabular}{ccccccc}
\hline $\begin{array}{c}\text { Nickel } \\
\text { subsulfide }\end{array}$ & & \multicolumn{5}{c}{ Percent of foci with growth in soft agar * } \\
\cline { 2 - 7 } $\begin{array}{c}\text { concentration } \\
\left(\boldsymbol{\mu g} / \mathbf{c m}^{2}\right)\end{array}$ & $\begin{array}{c}\text { Foci tested } \\
\text { in soft agar }\end{array}$ & $\mathbf{0}$ & $\mathbf{1 - 1 0}$ & $\mathbf{1 1 - 2 0}$ & $\mathbf{2 1 - 3 0}$ & $>\mathbf{3 0}$ \\
\hline 1 & 43 & $39 \%(17)$ & $26 \%(11)$ & $35 \%(15)$ & $0 \%(0)$ & $0 \%(0)$ \\
colonies/dish & colonies/dish & colonies/dish & colonies/dish & colonies/dish \\
\hline 2.5 & 27 & $0 \%(0)$ & $7 \%(2)$ & $67 \%(18)$ & $22 \%(6)$ & $4 \%(1)$ \\
5 & 44 & $30 \%(13)$ & $2 \%(1)$ & $7 \%(3)$ & $25 \%(11)$ & $36 \%(16)$ \\
\hline
\end{tabular}

* Data represents the percent of foci (number of foci) with $0,1-10,11-20,21-30$ or $>30$ soft agar colonies per dish.

A more likely explanation is that their exposure regimen may have been much more cytotoxic than our regimen and, as noted above in our and other's results [31,32], highly cytotoxic doses produce fewer foci, probably due to the increased toxicity. Interestingly, the cytotoxicity curves are similar 
between our two studies, but there is an important technical difference. In their cytotoxicity studies, they examined the impact of one round of a $48 \mathrm{~h}$ treatment, but in their transformation study, they exposed cells to six rounds of exposure and it is quite likely that the repeated exposure induced substantially more cytotoxicity, at least in an additive manner. Thus, the added cytotoxicity probably delayed their foci response. Of course, it is also possible that the differences reflect that our study cell line was immortalized with E6 and E7 oncoproteins from human papilloma virus and theirs was immortalized with large T-antigen from the SV40 virus.

The majority of nickel subsulfide-induced foci exhibited anchorage-independent growth, confirming the potency of nickel subsulfide-induced transformation (Table 3). These data also confirm that loss of contact inhibition and anchorage-independent growth are tightly correlated. It is difficult to compare our data to the one previous study in human bronchial epithelial cells due to differences in study design. By not isolating the foci, they essentially pooled all their foci together and tested the mixed population of nickel sulfide-treated cells for growth in soft agar [10]. They found a surprisingly high number of soft agar colonies in their nickel sulfide-treated cells; the highest dose had a colony forming efficiency of around $12 \%$ correlating to 120 colonies/dish [10]. The soft agar colony forming efficiency and colony numbers for our nickel subsulfide-induced foci were much lower with a maximum of 47 colonies observed per dish. One possible explanation for this difference is the differences between the cell lines or particulate nickel compounds. Unlike BEP2D cells, control $16 \mathrm{HBE}$ cells were able to form colonies in soft agar indicating these cells may be more susceptible to acquiring an anchorage-independent phenotype [10]. Another possible explanation is the difference in length of time before seeding into soft agar. The foci cells in this study were seeded into soft agar in as little as four passages after treatment while the nickel sulfide-treated cells in the previous study were seeded into soft agar after the $35^{\text {th }}$ passage [10]. Allowing the particulate nickel-treated cells to grow for 35 passages may allow for the clonal expansion and selection of faster growing, more aggressive transformed cells. In addition, particulate nickel-treated cells that exhibit chromosome instability may acquire more aberrations over time leading to increased transformation and anchorage-independent growth.

\section{Conclusions}

The mechanism of nickel-induced transformation is not fully understood. Our data here indicate that particulate nickel potently induced neoplastic transformation in human lung epithelial cells as shown by loss of contact inhibition and anchorage-independent growth. It also induced a concentration- and time-dependent increase in amount and spectrum of chromosome damage consistent with neoplastic transformation.

Looking forward, previous studies indicate nickel is a weak mutagen suggesting the mechanism does not involve base mutation changes [26,27]. Given that human lung cancers are known to contain structural chromosome changes, and in light of our findings, we hypothesize that chromosome instability may play a key role in the mechanism of particulate nickel-induced carcinogenesis. Furthermore, given the complexity of carcinogenesis and observations that nickel induces DNA methylation and histone acetylation changes, we further hypothesize a combination of genetic and epigenetic mechanisms are likely involved in particulate nickel-induced carcinogenesis. Future work 
will consider these hypotheses and investigate karyotypic, epigenetic and gene expression changes in the nickel subsulfide-induced foci.

\section{Acknowledgments}

We would like to thank Curtis C. Harris, National Cancer Institute, and Tom K. Hei, Columbia University, for the BEP2D cells. We would also like to thank Shouping Huang and Chris Gianios for administrative and technical support. This work was supported by ARO Grant \#W911NF-09-1-0296 (J.P.W.), and the Maine Center for Toxicology and Environmental Health.

\section{Conflicts of Interest}

The authors declare no conflict of interest.

\section{References}

1. Agency for Toxic Substances and Disease Registry. Toxicological Profile for Nickel; U.S. Department of Health and Human Services: Atlanta, GA, USA, 2005.

2. International Association for Research on Cancer. IARC Monographs on the Evaluation of Carcinogenic Risks to Humans. In Chromium, Nickel and Welding; International Agency for Research on Cancer, World Health Organization: Lyon, France, 1990; Volume 49, pp. 257-445.

3. International Committee on Nickel Carcinogenesis in Man. Report of the International Committee on Nickel Carcinogenesis in Man. Scandinavian J. Work Environ. Health 1990, 16, 1-82.

4. National Toxicology Program. (NTP) National Toxicology Program technical report on the toxicology and carcinogenesis studies of nickel oxide (CAS No. 1313-99-1) in F344/N rats and B6C3F1 mice (inhalation studies). Natl. Toxicol. Program Tech. Rep. Ser. 1996, 451, 1-381.

5. National Toxicology Program. (NTP) National Toxicology Program technical report on the toxicology and carcinogenesis studies of nickel subsulfide (CAS No. 12035-72-2) in F344/N rats and B6C3F1 mice (inhalation studies). Natl. Toxicol. Program Tech. Rep. Ser. 1996, 453, 1-365.

6. Abbracchio, M.P.; Simmons-Hansen, J.; Costa, M. Cytoplasmic dissolution of phagocytized crystalline nickel sulfide particles: A prerequisite for nuclear uptake of nickel. J. Toxicol. Environ. Health 1982, 9, 663-676.

7. Cangul, H.; Broday, L.; Salnikow, K.; Sutherland, J.; Peng, W.; Zhang, Q.; Poltaratsky, V.; Yee, H.; Zoroddu, M.A.; Costa, M. Molecular mechanisms of nickel carcinogenesis. Toxicol. Lett. 2002, 127, 69-75.

8. Sunderman, F.W., Jr.; Morgan, L.G.; Andersen, A.; Ashley, D.; Forouhar, F.A. Histopathology of sinonasal and lung cancers in nickel refinery workers. Ann. Clinical. Lab. Sci. 1989, 19, 44-50.

9. Akslen, L.A.; Myking, A.O.; Mørkve, O.; Gulsvik, A.; Raithel, H.J.; Schaller, K.H. Increased content of chromium and nickel in lung tissues from patients with bronchial carcinoma. Pathol. Res. Pract. 1990, 186, 717-722.

10. Ji, W.D.; Chen, J.K.; Lu, J.C.; Wu, Z.L.; Yi, F.; Feng, S.M. Alterations of FHIT gene and P16 gene in nickel transformed human bronchial epithelial cells. Biomed. Environ. Sci. 2006, 19, 277-284. 
11. Willey, J.C.; Broussoud, A.; Sleemi, A.; Bennet, W.P.; Cerutti, P.; Harris, C.C. Immortilization of normal human bronchial epithelial cells by human papillomaviruses 16 or 18. Cancer Res. 1991, 51, 5370-5377.

12. Costa, M.; Abbracchio, M.P.; Simmons-Hansen, J. Factors influencing the phagocytosis, neoplastic transformation, and cytotoxicity of particulate nickel compounds in tissue culture systems. Toxicol. Appl. Pharmacol. 1981, 60, 313-323.

13. Wise, J.P., Sr.; Wise, S.S.; Little, J.E. The cytotoxicity and genotoxicity of particulate and soluble hexavalent chromium in human lung cells. Mutat. Res. 2002, 517, 221-229.

14. Xie, H.; Holmes, A.L.; Wise, S.; Huang, S.; Peng, C.; Wise, J.P., Sr. Neoplastic transformation of human bronchial cells by lead chromate particles. Am. J. Respir. Cell Mol. Biol. 2007, 37, 544-552.

15. Rothman, K.J. Statistics in nonrandomized studies. Epidemiology 1990, 1, 417-418.

16. Hildebrand, H.F.; D’Hooghe, M.C.; Shirali, P.; Bailly, C.; Kerckaert, J.P. Uptake and biological transformation of beta $\mathrm{NiS}$ and alpha $\mathrm{Ni}_{3} \mathrm{~S}_{2}$ by human embryonic pulmonary epithelial cells (L132) in culture. Carcinogenesis 1990, 11, 1943-1950.

17. Sen, P.; Costa, M. Induction of chromosomal damage in Chinese hamster ovary cells by soluble and particulate nickel compounds: Preferential fragmentation of the heterochromatic long arm of the X-chromosome by carcinogenic crystalline NiS particles. Cancer Res. 1985, 45, 2320-2325.

18. Sen, P.; Costa, M. Pathway of nickel uptake influences its interaction with heterochromatic DNA. Toxicol. Appl. Pharmacol. 1986, 84, 278-285.

19. Sen, P.; Conway, K.; Costa, M. Comparison of the localization of chromosome damage induced by calcium chromate and nickel compounds. Cancer Res. 1987, 47, 2142-2147.

20. Lin, X.H.; Sugiyama, M.; Costa, M. Differences in the effect of vitamin E on nickel sulfide or nickel chloride-induced chromosomal aberrations in mammalian cells. Mutat. Res. 1991, 260, 159-164.

21. Landolph, J.R. Molecular mechanisms of transformation of C3H/10T1/2 C1 8 mouse embryo cells and diploid human fibroblasts by carcinogenic metal compounds. Environ. Health Perspect. 1994, 102, 119-125.

22. Huang, X.; Zhuang, Z.; Frenkel, K.; Klein, C.B.; Costa, M. The role of nickel and nickel-mediated reactive oxygen species in the mechanism of nickel carcinogenesis. Environ. Health Perspect. 1994, 102, 281-284.

23. Britten, R.J. Rate of DNA sequence evolution between different taxonomic groups. Science 1986, 231, 1393-1398.

24. Dávila-Rodríguez, M.I.; Cortés Gutiérrez, E.I.; Cerda Flores, R.M.; Pita, M.; Fernández, J.L.; López-Fernández, C.; Gosálvez, J. Constitutive heterochromatin polymorphisms in human chromosomes identified by whole comparative genomic hybridization. Eur. J. Histochem. 2011, 55, e28.

25. Murnane, J.P. Telomere dysfunction and chromosome instability. Mutat. Res. 2012, 730, $28-36$.

26. Biedermann, K.A.; Landolph, J.R. Induction of anchorage independence in human diploid foreskin fibroblasts by carcinogenic metal salts. Cancer Res. 1987, 47, 3815-3823.

27. Miura, T.; Patierno, S.R.; Sakuramoto, T.; Landolph, J.R. Morphological and neoplastic transformation of $\mathrm{C} 3 \mathrm{H} / 10 \mathrm{~T} 1 / 2 \mathrm{Cl} 8$ mouse embryo cells by insoluble carcinogenic nickel compounds. Environ. Mol. Mutagen. 1989, 14, 65-78. 
28. Lu, H.; Shi, X.; Costa, M.; Huang, C. Carcinogenic effect of nickel compounds. Mol. Cell. Biochem. 2005, 279, 45-67.

29. Zhang, Q.; Salnikow, K.; Kluz, T.; Chen, L.C.; Su, W.C.; Costa, M. Inhibition and reversal of nickel-induced transformation by the histone deacetylase inhibitor trichostatin A. Toxicol. Appl. Pharmacol. 2003, 192, 201-211.

30. Reznikoff, C.A.; Bertram, J.S.; Brankow, D.W.; Heidelberger, C. Quantitative and qualitative studies of chemical transformation of cloned $\mathrm{C} 3 \mathrm{H}$ mouse embryo cells sensitive to postconfluence inhibition of cell division. Cancer Res. 1973, 33, 3239-3249.

31. Xie, X.; LaCerte, C.; Thompson, W.D.; Wise, J.P., Sr. Depleted uranium induces neoplastic transformation in human lung epithelial cells. Chem. Res. Toxicol. 2010, 33, 373-378.

32. Patierno, S.R.; Banh, D.; Landolph, J.R. Transformation of C3H/10T1/2 mouse embryo cells to focus formation and anchorage independence by insoluble lead chromate but not soluble calcium chromate: relationship to mutagenesis and internalization of lead chromate particles. Cancer Res. 1988, 48, 5280-5288.

33. Carney, D.N.; Matthews, M.J.; Ihde, D.C.; Bunn, P.A., Jr.; Cohen, M.H.; Makuch, R.W.; Gazdar, A.F.; Minna, J.D. Influence of histologic subtype of small cell carcinoma of the lung on clinical presentation, response to therapy, and survival. J. Natl. Cancer Inst. 1980, 65, 1225-1230.

(C) 2013 by the authors; licensee MDPI, Basel, Switzerland. This article is an open access article distributed under the terms and conditions of the Creative Commons Attribution license (http://creativecommons.org/licenses/by/3.0/). 